\title{
HISTOLOGICAL AND MRI MARKERS OF WHITE MATTER DAMAGE IN FOCAL EPILEPSY
}

Francesco Deleo ${ }^{1}$, Maria Thom ${ }^{2}$, Luis Concha ${ }^{3}$, Andrea Bernasconi ${ }^{1}$, Boris Bernhardt ${ }^{1,4}$, Neda Bernasconi ${ }^{1}$

${ }^{I}$ NeuroImaging of Epilepsy Laboratory, Montreal Neurological Institute, McGill University, Canada

${ }^{2}$ Division of Neuropathology and Department of Clinical and Experimental Epilepsy, UCL Institute of Neurology, Queen Square, London WC1N 3BG, UK

${ }^{3}$ Instituto de Neurobiología, Universidad Nacional Autónoma de México, Querétaro, México

${ }^{4}$ Multimodal Imaging and Connectome Analysis Laboratory, Montreal Neurological Institute, McGill University, Canada 


\section{HISTOLOGICAL AND MRI MARKERS OF WHITE MATTER DAMAGE IN FOCAL EPILEPSY}

Francesco Deleo ${ }^{1}$, Maria Thom ${ }^{2}$, Luis Concha ${ }^{3}$, Andrea Bernasconi ${ }^{1}$, Boris Bernhardt ${ }^{1,4}$, Neda Bernasconi ${ }^{1}$

${ }^{I}$ NeuroImaging of Epilepsy Laboratory, Montreal Neurological Institute, McGill University, Canada

${ }^{2}$ Division of Neuropathology and Department of Clinical and Experimental Epilepsy, UCL Institute of Neurology, Queen Square, London WC1N 3BG, UK

${ }^{3}$ Instituto de Neurobiología, Universidad Nacional Autónoma de México, Querétaro, México

${ }^{4}$ Multimodal Imaging and Connectome Analysis Laboratory, Montreal Neurological Institute, McGill University, Canada

KEYWORDS: epilepsy, white matter, histology, MRI, diffusion MRI, connectomics

NUMBER OF WORDS: 4329

NUMBER OF FIGURES/TABLES: 1/3 


\begin{abstract}
Growing evidence highlights the importance of white matter in the pathogenesis of focal epilepsy. Ex vivo and post-mortem studies show pathological changes in epileptic patients in white matter myelination, axonal integrity, and cellular composition. Diffusion-weighted MRI and its analytical extensions, particularly diffusion tensor imaging (DTI), have been the most widely used technique to image the white matter in vivo for the last two decades, and have shown microstructural alterations in multiple tracts both in the vicinity and at distance from the epileptogenic focus. These techniques have also shown promising ability to predict cognitive status and response to pharmacological or surgical treatments. More recently, the hypothesis that focal epilepsy may be more adequately described as a system-level disorder has motivated a shift towards the study of macroscale brain connectivity. This review will cover emerging findings contributing to our understanding of white matter alterations in focal epilepsy, studied by means of histological and ultrastructural analyses, diffusion MRI, and large-scale network analysis. Focus is put on temporal lobe epilepsy and focal cortical dysplasia. This topic was addressed in a special interest group on neuroimaging at the $70^{\text {th }}$ annual meeting of the American Epilepsy Society, held in Houston December 2-6, 2016.
\end{abstract}




\section{Introduction}

Epilepsy has been long considered a disorder of the grey matter. However, in recent years there has been a rapid increase of converging findings pointing out the importance of the white matter in this condition. In this review article, we aim to provide an overview of most recent findings in the study of white matter, derived from histology, ex vivo and in vivo MRI, and connectomics. We will focus on investigations in temporal lobe epilepsy (TLE) and epilepsies related to focal cortical dysplasia (FCD), the most frequent forms of pharmacoresistant epilepsy.

This topic was addressed in a special interest group on neuroimaging at the $70^{\text {th }}$ annual meeting of the American Epilepsy Society, held in Houston December 2-6, 2016.

\section{Histopathology of the white matter}

White matter (WM) pathology is a hallmark feature of well-defined focal epilepsies, such as FCD type IIB and cortical tubers (Blümcke et al., 2011). The existence of similar but more subtle or diffuse abnormalities in "normal-appearing" WM as potential biomarkers for disease, has recently gained attention and been subjected to greater scrutiny (J. Y. Liu et al., 2014; Mühlebner et al., 2012; Reeves et al., 2016; Scholl et al., 2017; Schurr et al., 2017; Zucca et al., 2016). Pathological changes identified mainly correspond to abnormalities of myelination, axons or alteration of cellular composition.

The basic constituents of normal WM can be readily distinguished and quantified on histology sections from surgical epilepsy resections using a variety of standard techniques (Table 1, Fig. 1). It is important to consider the developmental maturation of the WM as well its capacity for regeneration and repair (Fancy et al., 2011; Semple et al., 2013). Completion of myelination in the human brain proceeds over several decades (Kinney et al., 1988) from pools of lineage-specific oligodendrocyte progenitor and precursor cells (OPC) that continue to differentiate into mature oligodendrocytes throughout adulthood, to maintain and repair myelin (Jakovcevski et al., 2009). Rates of myelination are influenced by neuronal activity (Jakovcevski et al., 2009) and axonal size (Fancy et al., 2011) among other factors and progress in a tract-dependent manner (Ullén, 2009), ultimately influencing axonal conduction velocity. The immediate subcortical region between the deep WM and the cortex represents a distinct anatomical compartment, containing additional Ufibers of Meynert (local cortical-cortical projections). This regions is therefore normally more 
densely myelinated and during development harbors maturing OPC (Jakovcevski et al., 2009) as well as the transient subplate neurons.

\section{1 Myelin content and oligodendroglia in focal cortical dysplasia}

Reduced myelination of the WM associated with FCD IIB was noted in the first descriptions of this pathology (Taylor et al., 1971) as well as variability in its extent and severity, with some cases being mild and restricted to the immediate sulcal subcortical U-fiber region (Fig. 1a). Whether this represent a primary and developmental failure of myelination (i.e., dysmyelination) was questioned (Blümcke et al., 2011). A quantitative reduction in myelinated fibers using myelinbasic protein has been confirmed in FCD IIB, even in those with subtle or no apparent MRI anomalies (Liu et al., 2013; Mühlebner et al., 2012; Shepherd et al., 2013). Milder changes have also been observed in peri-lesional WM (Zucca et al., 2016). Co-existing axonal pathology includes hypertrophic or giant axons visualized by light or electron microscopy (Liu et al., 2013; Shepherd et al., 2013; Zucca et al., 2016). Equivalent reduction of both axons and myelin, validated through quantitative analysis, (Shepherd et al., 2013) argues against a primary dysmyelinating process. Conversely, reduced and enlarged WM axons likely mirror the overlying cortical pathology with hypertrophic neurons. Interestingly an association between WM pathology and increased mTOR expression has recently been shown (Scholl et al., 2017). Myelin reduction has been shown to correlate with duration of epilepsy (Scholl et al., 2017; Shepherd et al., 2013) which could support progressive changes, although this relationship has not been confirmed by all studies (Zucca et al., 2016).

Different quantitative studies corroborate a reduction in oligodendroglial cells (defined as Olig2 positive cells) in the WM of FCD IIB (Mühlebner et al., 2012; Scholl et al., 2017; Shepherd et al., 2013; Zucca et al., 2016). Their number, however, has been shown to be proportionate to the density of myelinated axons present (Mühlebner et al., 2016, 2012; Scholl et al., 2017; Shepherd et al., 2013) and arguably appropriate for normal maintenance of myelination (Shepherd et al., 2013). However, reductions in oligodendroglial progenitor cell types (PDGFR $\alpha$ and NG2expressing cells) (Scholl et al., 2017; Shepherd et al., 2013), and in cases with myelin loss, activation of NG2-positive OPC was noted; these findings together with abnormal morphology of

oligodendroglia may be interpreted as delayed and defective maturation of these cells, contributing to FCD pathology (Mühlebner et al., 2012; Scholl et al., 2017; Zucca et al., 2016). A novel finding 
in a recent study of a series of frontal lobe epilepsy cases with normal appearing MRI was an increased density of Olig2 cells present in both the WM and deep cortex but in the absence of a myelin loss. This intriguing pathology was termed oligodendroglial hyperplasia and proposed as new entity in the spectrum of mild malformations of cortical development (Schurr et al., 2017), although whether this represents a primary or reactive process remains unclear.

\subsection{White matter pathology in temporal lobe epilepsy}

Interstitial neurons in normal adult WM represent the remnants of the developmental subplate (Judaš et al., 2010) and therefore some of the 'oldest' cortical neurons (Chun and Shatz, 1989). WM neurons are partitioned to the immediate subcortical zone, in the region of the U-fibers, but extend imperceptibly, in diminishing numbers, to the deeper WM (Suárez-Solá et al., 2009) (Fig. 1b). On conventional Nissl stains, these neurons show diverse morphology and neurochemistry and include glutamatergic, GABAergic and peptidergic neurons (Judaš et al., 2010) which can be highlighted with a range of immunomarkers (Suárez-Solá et al., 2009) (Table 1). Although their numbers diminish during maturation, they remain in significant numbers compared to non-primate brain. During development, they are critical to thalamic-cortical pathfinding connections. Their physiological function in adults remains uncertain, although they may play a role in the regulation of the microvasculature (Judaš et al., 2010) and coordination of inter-areal connectivity (SuárezSolá et al., 2009). Indeed interstitial neurons receive functional synaptic inputs from cortical neurons and generate action potentials (Shering and Lowenstein, 1994; Torres-Reveron and Friedlander, 2007) suggesting they are unlikely to be just a redundant developmental vestige.

In temporal lobe surgical specimens, quantitative evidence of increased numbers of neurons in otherwise apparently normal WM has been reported since the 1980s (Hardiman et al., 1988). Initially termed microdysgenesis, this observation had been confirmed by several subsequent studies (Eriksson et al., 2006, 2004; Kasper et al., 1999; Thom et al., 2001, 2000) and now termed mild malformation of cortical development type II (Blümcke et al., 2011). Yet, the precise definition remains poorly defined, hampered by a lack of cross-validation between published studies which have used different quantitative methods and assessed different neuronal types and regions of the WM (Blümcke et al., 2009). Furthermore, many of the published methods were impractical and time-consuming (Eriksson et al., 2006) and not readily applicable to the routine evaluation of large numbers of surgical cases. A recent study in TLE highlighted the potential of 
whole slide scanning and automated image analysis methodology to be as accurate as stereological methods with the added advantages of time-efficient unbiased analysis of the entire WM (J. Y. Liu et al., 2014) (Fig 1D). It is important to note, however, that digital pathology needs to be calibrated with 'in-house' normal control values to allow for correlation with neuroimaging and clinical outcomes.

The cause of increased interstitial neurons in epilepsy remains unexplained. Proposed theories include a reduction in the normal rate of elimination of subplate neurons during maturation or a true 'heterotopia' with arrested migration of neurons destined for the cortical plate. Elucidation of events may come through the study of the proportional representation of different interstitial neuronal phenotypes and their maturation. A recent study aimed to address this using Tbr1, a marker of immature subplate neurons (Richter et al., 2016) and showed that a lower proportion of interstitial neurons in TLE were Tbr1 positive compared to controls; this was interpreted as evidence of arrested neuronal migration. Increased WM neurogenesis from resident progenitor cells remains a plausible but still theoretical explanation for increased interstitial neurons (Lojewski et al., 2014). Finally, a contributing 'ex-vacuo' effect cannot be excluded, i.e., an apparent increase in the density of these cells as an epiphenomena of WM volume loss. In terms of contribution to epileptogenesis, increased 11C-flumazenil binding in the WM shown on positron emission tomography (Hammers et al., 2002) and altered dendritic pattern of labelling of GABA alsubunit on subcortical neurons, could indicate alteration of inhibitory circuits (Loup et al., 2009).

\section{MRI of the white matter}

By offering several sensitive and versatile whole-brain tissue markers, MRI has improved our ability to non-invasively detect epileptogenic lesions, and thus has revolutionized the management of patients with pharmacoresistant epilepsy, shifting the field from prevailing electroclinical correlation to a multidisciplinary approach (Bernasconi et al., 2011; Bernasconi and Bernasconi, 2014). It is important to note that any ex vivo biomarker of pathology in epilepsy, particularly if subtle and mild, has the potential to be translated in vivo via imaging. This should ideally be first tested through direct correlative studies to advance the understanding of the pathological basis. With respect to the WM, the so-called blurring or ill-defined grey-white boundaries observed on 
the MRI of TLE patients was shown to correspond to loss of myelinated axons in a 7T MRIhistology correlative study of surgical specimens (Garbelli et al., 2012). High resolution quantitative 9.4T MRI of epilepsy resections has also shown potential to detect subtle variations in WM myelination and interstitial neuronal number (Reeves et al., 2016) (Fig. 1g, i). Conversely, post-mortem brain studies, implementing similar quantitative methodologies can address the question of more extensive or contralateral damage along WM pathways in relation to a primary epileptogenic pathology (Blanc et al., 2011; Thom et al., 2005).

\subsection{In vivo studies based on diffusion MRI}

Diffusion-weighted MRI and its analytical extensions, particularly diffusion tensor imaging (DTI) (Basser et al., 1994), have been the most widely used technique to image the WM for the last two decades. Despite having relatively coarse spatial resolution (typically $2 \mathrm{~mm}$ ), diffusion-weighted MRI exploits the diffusion of water molecules to probe tissue microstructure, which is especially useful in coherently organized tissue (Beaulieu, 2002; Concha, 2014). The most-often reported metrics derived from diffusion weighted imaging are related to diffusion anisotropy (e.g., fractional anisotropy, FA), which tends to be high in regions where densely-packed axons have very similar orientations. Reduced diffusion anisotropy at the expense of increased radial diffusivity is interpreted as reduced axonal density and alteration of myelin architecture. Histological examination of the fornix and the temporal pole WM derived from surgical specimens of patients with TLE have confirmed these anomalies (Concha et al., 2010; Garbelli et al., 2012). Small caliber axons, in particular, are reduced in number in TLE patients (Ozdogmus et al., 2009; Tassi et al., 2009). Moreover, the orientational coherence of axons is reduced by the infiltration of oligodendrocytes, which are more common in regions of WM hyperintensity and may reflect an attempt to compensate for progressive myelin loss (Kendal et al., 1999; Stefanits et al., 2012). Other histological features, such as gliosis, may also play a role in altered water diffusion metrics.

\subsubsection{Applications in temporal lobe epilepsy}

DTI has so far been mainly applied to assess the microstructural integrity of WM tracts in TLE (Slinger et al., 2016), where abnormalities are evident in limbic structures, such as the fornix and cingulum (Concha et al., 2005), but also in the temporal lobe association tracts, such as the arcuate and uncinate fasciculi (Otte et al., 2012). Notably, a track-based segment analysis revealed a 
centrifugal pattern of mean diffusivity increases in major tracts carrying temporal lobe connections, where the degree of anomalies gradually tapered off as the tracts exited the temporal lobe (Concha et al., 2012; Keller et al., 2012). Interestingly, other WM structures outside of the temporal lobe, such as the corpus callosum and fronto-parietal pathways show diffusion abnormalities as well. Although changes are more marked ipsilateral to the seizure focus, there is considerable degree of bilateral involvement in a number of tracts (Concha et al., 2005; Otte et al., 2012). Studies on the effect of hemispheric laterality on diffusion metrics of WM in TLE patients have yielded conflicting results, with some reports showing more alterations in right-TLE patients than those with left-hemispheric onset (Kemmotsu et al., 2011; Liu et al., 2012), while others show the opposite (Ahmadi et al., 2009; Pustina et al., 2015).

Several factors appear to influence the degree and extent of diffusion abnormalities. Patients with severe mesiotemporal lobe sclerosis have more widespread and severe diffusion abnormalities than those with subtle pathology (Concha et al., 2009; Keller et al., 2013; Liu et al., 2012; Scanlon et al., 2013). Electron microscopy of fornix specimens obtained at surgery revealed considerably more damage in patient with severe neuronal loss and gliosis, consisting of reduced axonal density, and myelin abnormalities (Fig. 2) (Concha et al., 2010). Similar characteristics were noted in the fornix, bilaterally, in autopsy specimens from TLE patients (Ozdogmus et al., 2009). Axonal degeneration is expected in the fornix ipsilateral to mesiotemporal pathology and, although a fraction of axons cross the midline towards the contralateral hippocampus, neuronal death in the affected hippocampus may not be sufficient to explain bilateral abnormalities. The fact that diffusion anomalies may be present soon after diagnosis (Hutchinson et al., 2010) is suggestive of possible contributing role of neurodevelopmental processes; further evidence stems for animal models of epilepsy, suggesting their presence as a requisite for development of spontaneous seizures (Parekh et al., 2010). A recent study provided a multifactorial model of WM damage in TLE, in which genetic factors play a minimal role compared to the underlying pathology and effects of seizures (Vaughan et al., 2017).

\subsubsection{Applications in cortical malformations}

Compared to the large body of literature in TLE, fewer in vivo studies have addressed white matter alterations in FCD. Nevertheless, there is some evidence from voxel-based analysis for reduction of anisotropy and increased diffusivity (Eriksson et al., 2001; Fonseca et al., 2012). These 
alterations can be observed both subjacent to the MRI-visible lesion or diffuse across both hemispheres (Eriksson et al., 2001; Fonseca et al., 2012; Widjaja et al., 2009). Possible explanations of reduced anisotropy include differences in tissue composition between patients and controls due to pathology, abnormal myelination or the presence of ectopic neurons. Increased diffusivity has been interpreted as a defect of neurogenesis or cell loss resulting in increased extracellular space (Eriksson et al., 2001). Only few studies to date have used fiber tractography in FCD. One of the earliest showed both a reduction of the subcortical fibers and reduced connection between the subcortex and deep WM (Lee et al., 2004), while findings were contradicted in a later study (Widjaja et al., 2007).

\subsubsection{Relations to clinical and cognitive outcomes}

WM damage in TLE patients can also be a factor associated to a poor post-surgical outcome. A recent study using DTI and automated fiber quantification found that diffusion abnormalities in the ipsilateral dorsal fornix and in the contralateral parahippocampal bundle contribute to persistent postoperative seizures (Keller et al., 2017). Cognitive abilities are dependent on the orchestrated action of several brain regions interconnected by long association and commissural pathways, many of which are affected in epilepsy. It is thus not surprising that TLE patients may have cognitive deficits beyond temporal lobe functions (Hermann et al., 2007). Diffusion metrics of the superior longitudinal fasciculus, cingulum and temporal lobe WM are correlated with working memory performance (Winston et al., 2013). Similarly, diffusion anisotropy of the uncinate, arcuate and inferior fronto-occipital fascicles, as well as temporal cingulum positively correlate to verbal memory (Diehl et al., 2008; McDonald et al., 2014, 2008). Moreover, alterations of diffusion parameters in the temporal lobe WM is associated with delayed and immediate memory performances (Riley et al., 2010; Yogarajah et al., 2008). Preliminary data in patients with both idiopathic generalized and focal epilepsy show WM diffusion alterations already at disease onset (Hutchinson et al., 2010; Widjaja et al., 2013), which were shown to correlate with executive functions (Ekmekci et al., 2016). WM diffusion characteristics may thus provide valuable information to predict which patients are at higher risk of developing cognitive deficits, such that they can be prevented through more effective treatments. Additionally, if progressive WM abnormalities are secondary to ongoing seizures (Chiang et al., 2016; Govindan et al., 2008), then appropriate treatment could halt further cognitive deterioration. 


\subsection{Limitations of the tensor model and novel diffusion-based techniques}

The tensor model, which is used in the vast majority of studies, has provided valuable information regarding WM microstructure; yet it is necessary to recognize the many pitfalls of DTI (Jones and Cercignani, 2010). First and foremost, its incapacity to resolve distinct populations of fibers that cross within a single voxel, which leads to erroneous reduction of diffusion anisotropy. Second, the tensor model over-simplistically assumes that diffusion is Gaussian; in reality, the complex intracellular and extracellular environment causes the diffusion of water molecules to deviate considerably from this pattern, missing the opportunity to provide more information regarding the tissue microstructure. Fortunately, many alternative analytical methods have been proposed in the last decade that extend the capabilities of diffusion MRI and allow a more precise analysis compared to conventional tractography (Farquharson et al., 2013; Tournier et al., 2011). Among these advanced techniques, diffusion kurtosis imaging (DKI) and restriction spectrum imaging (RSI) have gained popularity for their ability to resolve crossing fibers and to quantify more specific intra-voxel tissue properties. DKI is an attempt to capture the non-gaussian diffusion behavior to better address the tissue heterogeneity (Wu and Cheung, 2010). RSI is based on a multi-compartment model that quantifies the degree to which diffusion heterogeneity within a voxel is driven by intra-axonal water versus extra-cellular diffusion, while accounting for fiber orientation (White et al., 2013). In TLE, in addition to revealing more marked diffusion profiles along ipsilateral WM fibers (Bonilha et al., 2015b; Glenn et al., 2016; Lee et al., 2013), these techniques have shown abnormalities in both grey and white matter extending to regions not detected by conventional DTI measures (Bonilha et al., 2015b; Gao et al., 2012). Similar findings were obtained with fixel-based analysis, a diffusion weighted MRI reconstruction technique which combines the measurements of fiber cross-sectional area, a measure of morphology, with microstructural information of fiber density (Raffelt et al., 2017), thereby providindg a sensitive marker of intra-axonal volume (Raffelt et al., 2017; Vaughan et al., 2017). Neurite orientation dispersion and density imaging, commonly referred to as NODDI (Zhang et al., 2012) is another advanced diffusion imaging reconstruction technique based on a multi-shell acquisition protocol that allows an estimation of intra- and extra-cellular volume fractions in order to measure neurites (i.e., dendrites and axons) morphology. This technique has the advantage to model both grey and white matter, a desired ability in the investigation of epilepsy; preliminary analysis has shown 
promising results in cortical malformations (Vargova et al., 2011; Winston et al., 2014). Finally, surface-based analysis of any of the above-mentioned metrics can overcome challenges in studying regions with complex fiber trajectories. This approach has been used to study the superficial WM that lies close beneath the cortical mantle and which contains both short-range association fibres and terminations of long-range tracts, particularly relevant for cognitive processes. In TLE, diffusion alterations of this compartment are found primarily in ipsilateral limbic regions (Liu et al., 2016). In extra-temporal epilepsy related to FCD Type II, subtle diffusion anomalies are found both at the lesional site and in the normal appearing peri-lesional WM (Hong et al., 2017a).

\section{Analysis of large-scale networks}

The hypothesis that focal epilepsy may be more adequately described as a system-level disorder can be tested using tools offered from steady advances in MRI techniques to probe macroscopic brain connectivity in vivo (Bullmore and Sporns, 2009; Bullmore and Bassett, 2011). Large-scale networks can be derived from systematic assessment of connections derived from neuroimaging modalities, including diffusion MRI tractography (Gong et al., 2009; Iturria-Medina et al., 2008), structural MRI covariance (Evans, 2013; He et al., 2008; Lerch et al., 2006; Seidlitz et al., 2017), and functional MRI connectivity (Achard et al., 2006; Biswal et al., 2010). While functional connectivity is derived from statistical associations between the time series of different elements in the network (Craddock et al., 2015), structural networks can be considered as the supporting hardwire (Jbabdi et al., 2015).

Systematic descriptions of connectivity between all pairs of regions (i.e., connectomes) can be studied using tools for complex system analysis, notably graph theory, a framework to formalize network topology (Bullmore and Sporns, 2009; Bullmore and Bassett, 2011; Mišić and Sporns, 2016; Stam, 2014; Whigham et al., 2016). In graph theory terms, a network is a collection of nodes (representing brain regions) interconnected by edges (representing structural/functional connections), and topological parameters characterize not only the nodes and edges themselves in terms of their embedding into the network, but also network organization as a whole (Fig. 3). In healthy populations, network analyses leveraging such methods highlighted core organizational principles of the human brain, including the co-existence of subnetwork integration as well as segregation (emphasized in the existence of short path lengths as well as high clustering) (Bullmore and Sporns, 2009; Stam, 2014; Whigham et al., 2016), the decomposability of the 
whole-brain network into a set of interacting communities (Bullmore and Bassett, 2011; Meunier et al., 2010), and the presence of hub regions that express a disproportionally high connectivity and that often mediate the communication between communities (Hagmann et al., 2008; Sporns et al., 2007; van den Heuvel and Sporns, 2011).

\subsection{Connectome studies in temporal lobe epilepsy}

Most connectome based studies have so far been carried out in TLE (Bernhardt et al., 2015, 2013). Collectively, findings have argued for a reorganization of macrolevel topological properties that may potentially provide useful diagnostic and prognostic information for the assessment of individual patients. One of the first WM connectome analyses in TLE focused on intra-limbic connectivity (Bonilha et al., 2012); the finding of increased clustering and nodal efficiency in patients compared to controls was interpreted as a reorganization towards a topology that may favor hyperexcitability. Increases in local clustering in regions close to the focus, together with breakdown of long-range connectivity have also been suggested by whole-brain connectome analysis (DeSalvo et al., 2014). On the other hand, decreases in local and global efficiency (suggestive of increased path length and decreased clustering) have also been reported, suggesting that some TLE cohorts may also present with a "breakdown" of both long- and short-range connections (M. Liu et al., 2014), a finding also supported by surface-based mapping of superficial WM diffusion parameters in TLE (Liu et al., 2016).

With regards to seizure focus laterality, a previous study suggested potential differences between left and right TLE patients at the level of WM connectomes (Besson et al., 2014), with more severe alterations in the former. Based on assessments suggesting that the magnitude of WM diffusion anomalies tapers off with increasing anatomical distance from the temporal lobe ipsilateral to the seizure focus (Concha et al., 2012; Keller et al., 2017), network parameters derived from diffusion MRI may have lateralization value (Kamiya et al., 2016). Recent studies have also utilized preoperative network markers to distinguish patients with postoperative seizure freedom from those with seizure recurrence (Bonilha et al., 2013). Predictive experiments have been carried out using standalone connectomic datasets (Munsell et al., 2015) or in combination with clinical data (Bonilha et al., 2015a), with overall promising findings. In light of work in healthy populations that utilize structural connectomes to simulate functional dynamics (Goñi et al., 2014; Honey et al., 2009; Misic et al., 2015), emerging data suggests that computational models of seizure spread and epileptogenicity based on structural connectomes may help localizing 
surgical targets (Hutchings et al., 2015) and possibly improve the prediction of post-surgical seizure outcome (Proix et al., 2017).

\subsection{Connectome studies in extra-temporal lobe epilepsy}

To date WM organization in cohorts with validated FCD has been seldom studied. A recent study employing structural covariance and functional connectivity analysis suggest marked network rearrangement particularly in FCD I (Hong et al., 2017b). In patients with frontal lobe epilepsy and suspected subtle dysplasia overall reductions of global and nodal efficiency have been observed, as well as network segregation (Vaessen et al., 2014; Widjaja et al., 2015). Given the macroscale analyses, it is likely that some connectome findings may relate to cognitive difficulties commonly seen in epileptic populations. Indeed, a structural connectivity study reported that patients with severe cognitive impairment may have more marked alterations in network topology compared with to healthy individuals as well as patients with only little cognitive impairment (Vaessen et al., 2012).

\section{Future directions}

Epilepsy is a network disorder and the white matter is the substrate connecting its various components. A proper conceptualization of this condition entails equal attention to both the grey and white matter at the site of the seizure focus and at distance from it. Microscopic studies have provided the structural basis for white matter pathology. Novel in vivo diffusion weighted MRI acquisition and reconstruction techniques, but also emerging imaging methods assessing myelin content (Bernhardt et al., 2017), deliver an increasingly comprehensive window to this pivotal compartment and its relationship to neuronal processes. Although initial studies have suggested the relevance of single markers of white matter integrity to clinical outcomes, a better understanding of this relationship would entail a combined analysis grey and white matter microstructure descriptors, connectome-level features, and lesional markers. In this context, machine-learning is considered a method of choice to extract critical features, patterns and relationships from such high-dimensional datasets that might otherwise be missed. Moreover, paralleling the move towards big data analyses in neuroscience, epilepsy research would benefit from data sharing initiatives to validate results and address new hypotheses. 


\section{References}

Achard, S., Salvador, R., Whitcher, B., Sucklig, J., Bullmore, E., 2006. A Resilient, LowFrequency, Small-World Human Brain Functional Network with Highly Connected Association Cortical Hubs. J. Neurosci. 26, 63-72.

Ahmadi, M.E., Hagler, D.J., McDonald, C.R., Tecoma, E.S., Iragui, V.J., Dale, A.M., Halgren, E., 2009. Side matters: diffusion tensor imaging tractography in left and right temporal lobe epilepsy. AJNR Am. J. Neuroradiol. 30, 1740-1747.

Basser, P.J., Mattiello, J., Lebihan, D., 1994. Estimation of the Effective Self-Diffusion Tensor from the NMR Spin Echo. J. Magn. Reson. Ser. B 103, 247-254.

Beaulieu, C., 2002. The basis of anisotropic water diffusion in the nervous system - a technical review. NMR Biomed. 15, 435-455.

Bernasconi, A., Bernasconi, N., Bernhardt, B.C., Schrader, D., 2011. Advances in MRI for "cryptogenic" epilepsies. Nat. Rev. Neurol. 7, 99-108.

Bernasconi, N., Bernasconi, A., 2014. Epilepsy: Imaging the epileptic brain-time for new standards. Nat. Rev. Neurol. 10, 133-134.

Bernhardt, B.C., Bonilha, L., Gross, D.W., 2015. Network analysis for a network disorder: The emerging role of graph theory in the study of epilepsy. Epilepsy Behav. 50, 162-170.

Bernhardt, B.C., Fadaie, F., Vos de Wael, R., Hong, S.-J., Liu, M., Guiot, M.C., Rudko, D.A., Bernasconi, A., Bernasconi, N., 2017. Preferential susceptibility of limbic cortices to microstructural damage in temporal lobe epilepsy: A quantitative T1 mapping study. Neuroimage.

Bernhardt, B.C., Hong, S., Bernasconi, A., Bernasconi, N., 2013. Imaging structural and functional brain networks in temporal lobe epilepsy. Front. Hum. Neurosci. 7, 624.

Besson, P., Dinkelacker, V., Valabregue, R., Thivard, L., Leclerc, X., Baulac, M., Sammler, D., Colliot, O., Lehéricy, S., Samson, S., Dupont, S., 2014. Structural connectivity differences in left and right temporal lobe epilepsy. Neuroimage 100, 135-144.

Biswal, B.B., Mennes, M., Zuo, X.-N., Gohel, S., Kelly, C., Smith, S.M., Beckmann, C.F., Adelstein, J.S., Buckner, R.L., Colcombe, S., Dogonowski, A., Ernst, M., Fair, D., Hampson, M., Hoptman, M.J., Hyde, J.S., Kiviniemi, V.J., Kötter, R., Li, S.-J., Lin, C.-P., Lowe, M.J., Mackay, C., Madden, D.J., Madsen, K.H., Margulies, D.S., Mayberg, H.S., McMahon, K., Monk, C.S., Mostofsky, S.H., Nagel, B.J., Pekar, J.J., Peltier, S.J., Petersen, S.E., Riedl, V., Rombouts, S.A.R.B., Rypma, B., Schlaggar, B.L., Schmidt, S., Seidler, R.D., Siegle, G.J., Sorg, C., Teng, G.-J., Veijola, J., Villringer, A., Walter, M., Wang, L., Weng, X.-C., Whitfield-gabrieli, S., Williamson, P., Windischberger, C., Zang, Y., Zhang, H., Castellanos, F.X., Milham, M.P., 2010. Toward discovery science of human brain function. Proc. Natl. Acad. Sci. U. S. A. 107, 4734-4739.

Blanc, F., Martinian, L., Liagkouras, I., Catarino, C., Sisodiya, S.M., Thom, M., 2011. Investigation of widespread neocortical pathology associated with hippocampal sclerosis in epilepsy: A postmortem study. Epilepsia 52, 10-21.

Blümcke, I., Thom, M., Aronica, E., Armstrong, D.D., Vinters, H. V, Palmini, A., Jacques, T.S., Avanzini, G., Barkovich, a J., Battaglia, G., Becker, A.J., Cepeda, C., Cendes, F., Colombo, N., Crino, P., Cross, J.H., Delalande, O., Dubeau, F., Duncan, J., Guerrini, R., Kahane, P., Mathern, G., Najm, I., Ozkara, C., Raybaud, C., Represa, A., Roper, S.N., Salamon, N., Schulze-Bonhage, A., Tassi, L., Vezzani, A., Spreafico, R., 2011. The clinicopathologic spectrum of focal cortical dysplasias: a consensus classification proposed by an ad hoc Task 
Force of the ILAE Diagnostic Methods Commission. Epilepsia 52, 158-174.

Blümcke, I., Vinters, H. V, Armstrong, D., Aronica, E., Thom, M., Spreafico, R., 2009. Malformations of cortical development and epilepsies: neuropathological findings with emphasis on focal cortical dysplasia. Epileptic Disord. 11, 181-193.

Bonilha, L., Helpern, J., Sainju, R., Nesland, T., Edwards, J., Glazier, S., Tabesh, A., 2013. Presurgical connectome and postsurgical seizure control in temporal lobe epilepsy. Neurology 81, 1704-1710.

Bonilha, L., Jensen, J.H., Baker, N., Breedlove, J., Nesland, T., Lin, J.J., Drane, D.L., Saindane, A.M., Binder, J.R., Kuzniecky, R.I., 2015a. The brain connectome as a personalized biomarker of seizure outcomes after temporal lobectomy. Neurology 84, 1846-1853.

Bonilha, L., Lee, C.-Y., Jensen, J.H., Tabesh, A., Spampinato, M. V, Edwards, J.C., Breedlove, J., Helpern, J.A., 2015b. Altered microstructure in temporal lobe epilepsy: a diffusional kurtosis imaging study. AJNR. Am. J. Neuroradiol. 36, 719-724.

Bonilha, L., Martz, G.U., Glazier, S.S., Edwards, J.C., 2012. Subtypes of medial temporal lobe epilepsy: Influence on temporal lobectomy outcomes? Epilepsia 53, 1-6.

Bullmore, E., Sporns, O., 2009. Complex brain networks: graph theoretical analysis of structural and functional systems. Nat. Rev. Neurosci. 10, 186-198.

Bullmore, E.T., Bassett, D.S., 2011. Brain Graphs: Graphical Models of the Human Brain Connectome. Annu. Rev. Clin. Psychol 7, 113-140.

Chiang, S., Levin, H.S., Wilde, E., Haneef, Z., 2016. White matter structural connectivity changes correlate with epilepsy duration in temporal lobe epilepsy. Epilepsy Res. 120, 37-46.

Chun, J.J.M., Shatz, C.J., 1989. Interstitial cells of the adult neocortical white matter are the remnant of the early generated subplate neuron population. J. Comp. Neurol. 282, 555-569.

Concha, L., 2014. A macroscopic view of microstructure: using diffusion-weighted images to infer damage, repair, and plasticity of white matter. Neuroscience 276, 14-28.

Concha, L., Beaulieu, C., Collins, D.L., Gross, D.W., 2009. White-matter diffusion abnormalities in temporal-lobe epilepsy with and without mesial temporal sclerosis. J. Neurol. Neurosurg. Psychiatry 80, 312-319.

Concha, L., Beaulieu, C., Gross, D.W., 2005. Bilateral limbic diffusion abnormalities in unilateral temporal lobe epilepsy. Ann. Neurol. 57, 188-196.

Concha, L., Kim, H., Bernasconi, A., Bernhardt, B.C., Bernasconi, N., 2012. Spatial patterns of water diffusion along white matter tracts in temporal lobe epilepsy. Neurology 79, 455-462.

Concha, L., Livy, D.J., Beaulieu, C., Wheatley, B.M., Gross, D.W., 2010. In Vivo Diffusion Tensor Imaging and Histopathology of the Fimbria-Fornix in Temporal Lobe Epilepsy. J. Neurosci. 30, 996-1002.

Craddock, R.C., Tungaraza, R.L., Milham, M.P., 2015. Connectomics and new approaches for analyzing human brain functional connectivity. Gigascience 4, 13.

DeSalvo, M.N., Douw, L., Tanaka, N., Reinsberger, C., Stufflebeam, S.M., 2014. Altered structural connectome in temporal lobe epilepsy. Radiology 270, 842-848.

Diehl, B., Busch, R.M., Duncan, J.S., Piao, Z., Tkach, J., Lüders, H.O., 2008. Abnormalities in diffusion tensor imaging of the uncinate fasciculus relate to reduced memory in temporal lobe epilepsy. Epilepsia 49, 1409-1418.

Ekmekci, B., Bulut, H.T., Gümüştaş, F., Yıldırım, A., Kuştepe, A., 2016. The relationship between white matter abnormalities and cognitive functions in new-onset juvenile myoclonic epilepsy. Epilepsy Behav. 62, 166-170.

Eriksson, S.H., Free, S.L., Thom, M., Martinian, L., Sisodiya, S.M., 2006. Methodological aspects 
of 3D and automated 2D analyses of white matter neuronal density in temporal lobe epilepsy. Neuropathol. Appl. Neurobiol. 32, 260-270.

Eriksson, S.H., Nordborg, C., Thom, M., Sisodiya, S.M., 2004. Microdysgenesis in mesial temporal lobe epilepsy. Ann. Neurol. 55, 596-597.

Eriksson, S.H., Rugg-Gunn, F.J., Symms, M.R., Barker, G.J., Duncan, J.S., 2001. Diffusion tensor imaging in patients with epilepsy and malformations of cortical development. Brain 124, 617-626.

Evans, A.C., 2013. Networks of anatomical covariance. Neuroimage 80, 489-504.

Fancy, S.P.J., Chan, J.R., Baranzini, S.E., Franklin, R.J.M., Rowitch, D.H., 2011. Myelin Regeneration: A Recapitulation of Development? Annu. Rev. Neurosci. 34, 21-43.

Farquharson, S., Tournier, J.-D., Calamante, F., Fabinyi, G., Schneider-Kolsky, M., Jackson, G.D., Connelly, A., 2013. White matter fiber tractography: why we need to move beyond DTI. J. Neurosurg. 118, 1367-1377.

Fonseca, V. de C., Yasuda, C.L., Tedeschi, G.G., Betting, L.E., Cendes, F., 2012. White matter abnormalities in patients with focal cortical dysplasia revealed by diffusion tensor imaging analysis in a voxelwise approach. Front. Neurol. 3, 121.

Gao, Y., Zhang, Y., Wong, C.-S., Wu, P.-M., Zhang, Z., Gao, J., Qiu, D., Huang, B., 2012. Diffusion abnormalities in temporal lobes of children with temporal lobe epilepsy: a preliminary diffusional kurtosis imaging study and comparison with diffusion tensor imaging. NMR Biomed. 25, 1369-1377.

Garbelli, R., Milesi, G., Medici, V., Villani, F., Didato, G., Deleo, F., D’Incerti, L., Morbin, M., Mazzoleni, G., Giovagnoli, A.R., Parente, A., Zucca, I., Mastropietro, A., Spreafico, R., 2012. Blurring in patients with temporal lobe epilepsy: clinical, high-field imaging and ultrastructural study. Brain 135, 2337-2349.

Glenn, G.R., Jensen, J.H., Helpern, J.A., Spampinato, M. V, Kuzniecky, R., Keller, S.S., Bonilha, L., 2016. Epilepsy-related cytoarchitectonic abnormalities along white matter pathways. J. Neurol. Neurosurg. Psychiatry 87, 930-936.

Gong, G., He, Y., Concha, L., Lebel, C., Gross, D.W., Evans, A.C., Beaulieu, C., 2009. Mapping anatomical connectivity patterns of human cerebral cortex using in vivo diffusion tensor imaging tractography. Cereb Cortex 19, 524-536.

Goñi, J., van den Heuvel, M.P., Avena-Koenigsberger, A., Velez de Mendizabal, N., Betzel, R.F., Griffa, A., Hagmann, P., Corominas-Murtra, B., Thiran, J.-P., Sporns, O., 2014. Resting-brain functional connectivity predicted by analytic measures of network communication. Proc. Natl. Acad. Sci. U. S. A. 111, 833-838.

Govindan, R.M., Makki, M.I., Sundaram, S.K., Juhász, C., Chugani, H.T., 2008. Diffusion tensor analysis of temporal and extra-temporal lobe tracts in temporal lobe epilepsy. Epilepsy Res. $80,30-41$.

Hagmann, P., Cammoun, L., Gigandet, X., Meuli, R., Honey, C.J., Van Wedeen, J., Sporns, O., 2008. Mapping the structural core of human cerebral cortex. PLoS Biol. 6, 1479-1493.

Hammers, A., Koepp, M.J., Hurlemann, R., Thom, M., Richardson, M.P., Brooks, D.J., Duncan, J.S., 2002. Abnormalities of grey and white matter [11C]flumazenil binding in temporal lobe epilepsy with normal MRI. Brain 125, 2257-2271.

Hardiman, O., Burke, T., Phillips, J., Murphy, S., O’Moore, B., Staunton, H., Farrell, M.A., 1988. Microdysgenesis in resected temporal neocortex: Incidence and clinical significance in focal epilepsy. Neurology 38, 1041-1047.

He, Y., Chen, Z., Evans, A., 2008. Structural insights into aberrant topological patterns of large- 
scale cortical networks in Alzheimer's disease. J. Neurosci. 28, 4756-4766.

Hermann, B., Seidenberg, M., Lee, E.-J., Chan, F., Rutecki, P., 2007. Cognitive phenotypes in temporal lobe epilepsy. J. Int. Neuropsychol. Soc. 13, 12-20.

Honey, C.J., Sporns, O., Cammoun, L., Gigandet, X., Thiran, J.P., Meuli, R., Hagmann, P., Honey, C.J., Sporns, O., Sporns, O., Cammoun, L., Cammoun, L., Gigandet, X., Gigandet, X., Thiran, J.P., Thiran, J.P., Meuli, R., Meuli, R., Hagmann, P., Hagmann, P., 2009. Predicting human resting-state functional connectivity from structural connectivity. Proc. Natl. Acad. Sci. U. S. A. 106, 2035-2040.

Hong, S.-J., Bernhardt, B.C., Caldairou, B., Hall, J.A., Guiot, M.C., Schrader, D., Bernasconi, N., Bernasconi, A., 2017a. Multimodal MRI profiling of focal cortical dysplasia type II. Neurology 88, 734-742.

Hong, S.-J., Bernhardt, B.C., Gill, R.S., Bernasconi, N., Bernasconi, A., 2017b. The spectrum of structural and functional network alterations in malformations of cortical development. Brain 140, 2133-2143.

Hutchings, F., Han, C.E., Keller, S.S., Weber, B., Taylor, P.N., Kaiser, M., 2015. Predicting Surgery Targets in Temporal Lobe Epilepsy through Structural Connectome Based Simulations. PLOS Comput. Biol. 11, e1004642.

Hutchinson, E., Pulsipher, D., Dabbs, K., Myers y Gutierrez, A., Sheth, R., Jones, J., Seidenberg, M., Meyerand, E., Hermann, B., 2010. Children with new-onset epilepsy exhibit diffusion abnormalities in cerebral white matter in the absence of volumetric differences. Epilepsy Res. 88, 208-214.

Iturria-Medina, Y., Sotero, R.C., Canales-Rodríguez, E.J., Alemán-Gómez, Y., Melie-García, L., 2008. Studying the human brain anatomical network via diffusion-weighted MRI and Graph Theory. Neuroimage 40, 1064-1076.

Jakovcevski, I., Filipovic, R., Mo, Z., Rakic, S., Zecevic, N., 2009. Oligodendrocyte development and the onset of myelination in the human fetal brain. Front. Neuroanat. 3, 5.

Jbabdi, S., Sotiropoulos, S.N., Haber, S.N., Van Essen, D.C., Behrens, T.E., Essen, D.C. Van, Behrens, T.E., 2015. Measuring macroscopic brain connections in vivo. Nat. Neurosci. 18, 1546-1555.

Jones, D.K., Cercignani, M., 2010. Twenty-five pitfalls in the analysis of diffusion MRI data. NMR Biomed. 23, 803-820.

Judaš, M., Sedmak, G., Pletikos, M., Jovanov-Milošević, N., 2010. Populations of subplate and interstitial neurons in fetal and adult human telencephalon. J. Anat. 217, 381-399.

Kamiya, K., Amemiya, S., Suzuki, Y., Kunii, N., Kawai, K., Mori, H., Kunimatsu, A., Saito, N., Aoki, S., Ohtomo, K., 2016. Machine Learning of DTI Structural Brain Connectomes for Lateralization of Temporal Lobe Epilepsy. Magn. Reson. Med. Sci. 15, 121-129.

Kasper, B.S., Stefan, H., Buchfelder, M., Paulus, W., 1999. Temporal lobe microdysgenesis in epilepsy versus control brains. J. Neuropathol. Exp. Neurol. 58, 22-28.

Keller, S.S., Ahrens, T., Mohammadi, S., Gerdes, J.S., Möddel, G., Kellinghaus, C., Kugel, H., Weber, B., Ringelstein, E.B., Deppe, M., 2013. Voxel-based statistical analysis of fractional anisotropy and mean diffusivity in patients with unilateral temporal lobe epilepsy of unknown cause. J. Neuroimaging 23, 352-359.

Keller, S.S., Glenn, G.R., Weber, B., Kreilkamp, B.A.K., Jensen, J.H., Helpern, J.A., Wagner, J., Barker, G.J., Richardson, M.P., Bonilha, L., 2017. Preoperative automated fibre quantification predicts postoperative seizure outcome in temporal lobe epilepsy. Brain 140, $68-82$. 
Keller, S.S., Schoene-Bake, J.-C., Gerdes, J.S., Weber, B., Deppe, M., 2012. Concomitant fractional anisotropy and volumetric abnormalities in temporal lobe epilepsy: cross-sectional evidence for progressive neurologic injury. PLoS One 7, e46791.

Kemmotsu, N., Girard, H.M., Bernhardt, B.C., Bonilha, L., Lin, J.J., Tecoma, E.S., Iragui, V.J., Hagler, D.J., Halgren, E., McDonald, C.R., 2011. MRI analysis in temporal lobe epilepsy: cortical thinning and white matter disruptions are related to side of seizure onset. Epilepsia 52, 2257-2266.

Kendal, C., Everall, I., Polkey, C., Al-Sarraj, S., 1999. Glial cell changes in the white matter in temporal lobe epilepsy. Epilepsy Res. 36, 43-51.

Kinney, H.C., Brody, B.A., Kloman, A.S., Gilles, F.H., 1988. Sequence of central nervous system myelination in human infancy. II. Patterns of myelination in autopsied infants. J. Neuropathol. Exp. Neurol. 47, 217-234.

Lee, C.-Y., Tabesh, A., Benitez, A., Helpern, J.A., Jensen, J.H., Bonilha, L., 2013. Microstructural integrity of early- versus late-myelinating white matter tracts in medial temporal lobe epilepsy. Epilepsia 54, 1801-1809.

Lee, S.K., Kim, D.I., Mori, S., Kim, J., Kim, H.D., Heo, K., Lee, B.I., 2004. Diffusion tensor MRI visualizes decreased subcortical fiber connectivity in focal cortical dysplasia. Neuroimage $22,1826-1829$.

Lerch, J.P., Worsley, K., Shaw, W.P., Greenstein, D.K., Lenroot, R.K., Giedd, J., Evans, A.C., 2006. Mapping anatomical correlations across cerebral cortex (MACACC) using cortical thickness from MRI. Neuroimage 31, 993-1003.

Liu, J.Y., Ellis, M., Brooke-Ball, H., de Tisi, J., Eriksson, S.H., Brandner, S., Sisodiya, S.M., Thom, M., 2014. High-throughput, automated quantification of white matter neurons in mild malformation of cortical development in epilepsy. Acta Neuropathol. Commun. 2, 72.

Liu, M., Bernhardt, B.C., Hong, S.J., Caldairou, B., Bernasconi, A., Bernasconi, N., 2016. The superficial white matter in temporal lobe epilepsy: A key link between structural and functional network disruptions. Brain 139, 2431-2440.

Liu, M., Chen, Z., Beaulieu, C., Gross, D.W., 2014. Disrupted anatomic white matter network in left mesial temporal lobe epilepsy. Epilepsia 55, 674-682.

Liu, M., Concha, L., Lebel, C., Beaulieu, C., Gross, D.W., 2012. Mesial temporal sclerosis is linked with more widespread white matter changes in temporal lobe epilepsy. NeuroImage Clin. 1, 99-105.

Liu, M., Gross, D.W., Wheatley, B.M., Concha, L., Beaulieu, C., 2013. The acute phase of Wallerian degeneration: longitudinal diffusion tensor imaging of the fornix following temporal lobe surgery. Neuroimage 74, 128-139.

Lockwood-Estrin, G., Thom, M., Focke, N.K., Symms, M.R., Martinian, L., Sisodiya, S.M., Duncan, J.S., Eriksson, S.H., 2012. Correlating 3T MRI and histopathology in patients undergoing epilepsy surgery. J. Neurosci. Methods 205, 182-189.

Lojewski, X., Hermann, A., Wegner, F., Araúzo-Bravo, M.J., Hallmeyer-Elgner, S., Kirsch, M., Schwarz, J., Schöler, H.R., Storch, A., 2014. Human adult white matter progenitor cells are multipotent neuroprogenitors similar to adult hippocampal progenitors. Stem Cells Transl. Med. 3, 458-469.

Loup, F., Picard, F., Yonekawa, Y., Wieser, H.G., Fritschy, J.M., 2009. Selective changes in GABAA receptor subtypes in white matter neurons of patients with focal epilepsy. Brain 132, 2449-2463.

McDonald, C.R., Ahmadi, M.E., Hagler, D.J., Tecoma, E.S., Iragui, V.J., Gharapetian, L., Dale, 
A.M., Halgren, E., 2008. Diffusion tensor imaging correlates of memory and language impairments in temporal lobe epilepsy. Neurology 71, 1869-1876.

McDonald, C.R., Leyden, K.M., Hagler, D.J., Kucukboyaci, N.E., Kemmotsu, N., Tecoma, E.S., Iragui, V.J., 2014. White matter microstructure complements morphometry for predicting verbal memory in epilepsy. Cortex. 58, 139-150.

Meunier, D., Lambiotte, R., Bullmore, E.T., 2010. Modular and Hierarchically Modular Organization of Brain Networks. Front. Neurosci. 4.

Misic, B., Betzel, R.F.F., Nematzadeh, A., Goni, J., Griffa, A., Hagmann, P., Flammini, A., Ahn, Y.-Y., Sporns, O., Mišić, B., Betzel, R.F.F., Nematzadeh, A., Goñi, J., Griffa, A., Hagmann, P., Flammini, A., Ahn, Y.-Y., Sporns, O., 2015. Cooperative and Competitive Spreading Dynamics on the Human Connectome. Neuron 86, 1518-1529.

Mišić, B., Sporns, O., 2016. From regions to connections and networks: New bridges between brain and behavior. Curr. Opin. Neurobiol. 40, 1-7.

Mühlebner, A., Coras, R., Kobow, K., Feucht, M., Czech, T., Stefan, H., Weigel, D., Buchfelder, M., Holthausen, H., Pieper, T., Kudernatsch, M., Blümcke, I., 2012. Neuropathologic measurements in focal cortical dysplasias: Validation of the ILAE 2011 classification system and diagnostic implications for MRI. Acta Neuropathol. 123, 259-272.

Mühlebner, A., van Scheppingen, J., Hulshof, H.M., Scholl, T., Iyer, A.M., Anink, J.J., van den Ouweland, A.M.W., Nellist, M.D., Jansen, F.E., Spliet, W.G.M., Krsek, P., Benova, B., Zamecnik, J., Crino, P.B., Prayer, D., Czech, T., Wöhrer, A., Rahimi, J., Höftberger, R., Hainfellner, J.A., Feucht, M., Aronica, E., 2016. Novel Histopathological Patterns in Cortical Tubers of Epilepsy Surgery Patients with Tuberous Sclerosis Complex. PLoS One 11, e0157396.

Munsell, B.C., Wee, C.-Y., Keller, S.S., Weber, B., Elger, C., da Silva, L.A.T., Nesland, T., Styner, M., Shen, D., Bonilha, L., Tomaz Da Silva, L.A., Nesland, T., Styner, M., Shen, D., Bonilha, L., 2015. Evaluation of machine learning algorithms for treatment outcome prediction in patients with epilepsy based on structural connectome data. Neuroimage 118, 219-230.

Otte, W.M., van Eijsden, P., Sander, J.W., Duncan, J.S., Dijkhuizen, R.M., Braun, K.P.J., 2012. A meta-analysis of white matter changes in temporal lobe epilepsy as studied with diffusion tensor imaging. Epilepsia 53, 659-667.

Ozdogmus, O., Cavdar, S., Ersoy, Y., Ercan, F., Uzun, I., 2009. A preliminary study, using electron and light-microscopic methods, of axon numbers in the fornix in autopsies of patients with temporal lobe epilepsy. Anat. Sci. Int. 84, 2-6.

Parekh, M.B., Carney, P.R., Sepulveda, H., Norman, W., King, M., Mareci, T.H., 2010. Early MR diffusion and relaxation changes in the parahippocampal gyrus precede the onset of spontaneous seizures in an animal model of chronic limbic epilepsy. Exp. Neurol. 224, 258270.

Proix, T., Bartolomei, F., Guye, M., Jirsa, V.K., 2017. Individual brain structure and modelling predict seizure propagation. Brain 140, 641-654.

Pustina, D., Doucet, G., Sperling, M., Sharan, A., Tracy, J., 2015. Increased microstructural white matter correlations in left, but not right, temporal lobe epilepsy. Hum. Brain Mapp. 36, 8598.

Raffelt, D.A., Tournier, J.-D., Smith, R.E., Vaughan, D.N., Jackson, G., Ridgway, G.R., Connelly, A., 2017. Investigating white matter fibre density and morphology using fixel-based analysis. Neuroimage 144, 58-73.

Reeves, C., Tachrount, M., Thomas, D., Michalak, Z., Liu, J., Ellis, M., Diehl, B., Miserocchi, A., 
McEvoy, A.W., Eriksson, S., Yousry, T., Thom, M., 2016. Combined Ex Vivo 9.4T MRI and Quantitative Histopathological Study in Normal and Pathological Neocortical Resections in Focal Epilepsy. Brain Pathol. 26, 319-333.

Richter, Z., Janszky, J., Sètàlò, G., Horvàth, R., Horvàth, Z., Dòczi, T., Seress, L., A 'brahàm, H., 2016. Characterization of neurons in the cortical white matter in human temporal lobe epilepsy. Neuroscience 333, 140-150.

Riley, J.D., Franklin, D.L., Choi, V., Kim, R.C., Binder, D.K., Cramer, S.C., Lin, J.J., 2010. Altered white matter integrity in temporal lobe epilepsy: association with cognitive and clinical profiles. Epilepsia 51, 536-545.

Scanlon, C., Mueller, S.G., Cheong, I., Hartig, M., Weiner, M.W., Laxer, K.D., 2013. Grey and white matter abnormalities in temporal lobe epilepsy with and without mesial temporal sclerosis. J. Neurol. 260, 2320-2329.

Scholl, T., Mühlebner, A., Ricken, G., Gruber, V., Fabing, A., Samueli, S., Gröppel, G., Dorfer, C., Czech, T., Hainfellner, J.A., Prabowo, A.S., Reinten, R.J., Hoogendijk, L., Anink, J.J., Aronica, E., Feucht, M., 2017. Impaired oligodendroglial turnover is associated with myelin pathology in focal cortical dysplasia and tuberous sclerosis complex. Brain Pathol. 27, 770780.

Schurr, J., Coras, R., Rössler, K., Pieper, T., Kudernatsch, M., Holthausen, H., Winkler, P., Woermann, F., Bien, C.G., Polster, T., Schulz, R., Kalbhenn, T., Urbach, H., Becker, A., Grunwald, T., Huppertz, H.-J., Gil-Nagel, A., Toledano, R., Feucht, M., Mühlebner, A., Czech, T., Blümcke, I., 2017. Mild Malformation of Cortical Development with Oligodendroglial Hyperplasia in Frontal Lobe Epilepsy: A New Clinico-Pathological Entity. Brain Pathol. 27, 26-35.

Seidlitz, J., Váša, F., Shinn, M., Romero-garcia, R., Whitaker, K.J., Vértes, P.E., Reardon, P.K., Clasen, L., Messinger, A., Leopold, D.A., Fonagy, P., Dolan, R.J., Jones, P.B., Goodyer, I.M., the NSPN Consortium, Raznahan, A., Bullmore, E.T., 2017. Morphometric Similarity Networks Detect Microscale Cortical Organisation and Predict Inter-Individual Cognitive Variation. bioRxiv 1-63.

Semple, B.D., Blomgren, K., Gimlin, K., Ferriero, D.M., Noble-Haeusslein, L.J., 2013. Brain development in rodents and humans: Identifying benchmarks of maturation and vulnerability to injury across species. Prog. Neurobiol. 106-107, 1-16.

Shepherd, C., Liu, J., Goc, J., Martinian, L., Jacques, T.S., Sisodiya, S.M., Thom, M., 2013. A quantitative study of white matter hypomyelination and oligodendroglial maturation in focal cortical dysplasia type II. Epilepsia 54, 898-908.

Shering, A.F., Lowenstein, P.R., 1994. Neocortex provides direct synaptic input to interstitial neurons of the intermediate zone of kittens and white matter of cats: a light and electron microscopic study. J. Comp. Neurol. 347, 433-443.

Slinger, G., Sinke, M.R.T.T., Braun, K.P.J.J., Otte, W.M., 2016. White matter abnormalities at a regional and voxel level in focal and generalized epilepsy: A systematic review and metaanalysis. NeuroImage Clin. 12, 902-909.

Sporns, O., Honey, C.J., Kötter, R., 2007. Identification and classification of hubs in brain networks. PLoS One 2, e1049.

Stam, C.J., 2014. Modern network science of neurological disorders. Nat. Rev. Neurosci. 15, 683695.

Stefanits, H., Czech, T., Pataraia, E., Baumgartner, C., Derhaschnig, N., Slana, A., Kovacs, G.G., 2012. Prominent oligodendroglial response in surgical specimens of patients with temporal 
lobe epilepsy. Clin. Neuropathol. 31, 409-417.

Suárez-Solá, M.L., González-Delgado, F.J., Pueyo-Morlans, M., Medina-Bolívar, O.C., Hernández-Acosta, N.C., González-Gómez, M., Meyer, G., 2009. Neurons in the white matter of the adult human neocortex. Front. Neuroanat. 3, 7.

Tassi, L., Meroni, A., Deleo, F., Villani, F., Mai, R., Lo Russo, G., Colombo, N., Avanzini, G., Falcone, C., Bramerio, M., Citterio, A., Garbelli, R., Spreafico, R., 2009. Temporal lobe epilepsy: neuropathological and clinical correlations in 243 surgically treated patients. Epileptic Disord. 11, 281-292.

Taylor, D.C., Falconer, M. a, Bruton, C.J., Corsellis, J. a, 1971. Focal dysplasia of the cerebral cortex in epilepsy. J. Neurol. Neurosurg. Psychiatry 34, 369-387.

Thom, M., Blümcke, I., Aronica, E., 2012. Long-term epilepsy-associated tumors. Brain Pathol. $22,350-379$.

Thom, M., Holton, J.L., D’Arrigo, C., Griffin, B., Beckett, A., Sisodiya, S., Alexiou, D., Sander, J.W., 2000. Microdysgenesis with abnormal cortical myelinated fibres in temporal lobe epilepsy: a histopathological study with calbindin D-28-K immunohistochemistry. Neuropathol. Appl. Neurobiol. 26, 251-257.

Thom, M., Sisodiya, S., Harkness, W., Scaravilli, F., 2001. Microdysgenesis in temporal lobe epilepsy. A quantitative and immunohistochemical study of white matter neurones. Brain 124, 2299-2309.

Thom, M., Zhou, J., Martinian, L., Sisodiya, S., 2005. Quantitative post-mortem study of the hippocampus in chronic epilepsy: seizures do not inevitably cause neuronal loss. Brain 128, 1344-1357.

Torres-Reveron, J., Friedlander, M.J., 2007. Properties of persistent postnatal cortical subplate neurons. J. Neurosci. 27, 9962-9974.

Tournier, J.-D., Mori, S., Leemans, A., 2011. Diffusion tensor imaging and beyond. Magn. Reson. Med. 65, 1532-1556.

Ullén, F., 2009. Is activity regulation of late myelination a plastic mechanism in the human nervous system? Neuron Glia Biol. 5, 29-34.

Vaessen, M.J., Jansen, J.F.A., Braakman, H.M.H., Hofman, P.A.M., De Louw, A., Aldenkamp, A.P., Backes, W.H., 2014. Functional and structural network impairment in childhood frontal lobe epilepsy. PLoS One 9, 1-10.

Vaessen, M.J., Jansen, J.F.A., Vlooswijk, M.C.G., Hofman, P.A.M., Majoie, H.J.M., Aldenkamp, A.P., Backes, W.H., 2012. White matter network abnormalities are associated with cognitive decline in chronic epilepsy. Cereb. Cortex 22, 2139-2147.

van den Heuvel, M.P., Sporns, O., 2011. Rich-club organization of the human connectome. J. Neurosci. 31, 15775-15786.

Vargova, L., Homola, A., Cicanic, M., Kuncova, K., Krsek, P., Marusic, P., Sykova, E., Zamecnik, J., 2011. The diffusion parameters of the extracellular space are altered in focal cortical dysplasias. Neurosci. Lett. 499, 19-23.

Vaughan, D.N., Raffelt, D., Curwood, E., Tsai, M.-H., Tournier, J.-D., Connelly, A., Jackson, G.D., 2017. Tract-specific atrophy in focal epilepsy: disease, genetics or seizures? Ann. Neurol. 81, 240-250.

Whigham, P.A., Dick, G., Parry, M., 2016. Network rewiring dynamics with convergence towards a star network. Proceedings. Math. Phys. Eng. Sci. 472, 20160236.

White, N.S., Leergaard, T.B., D’Arceuil, H., Bjaalie, J.G., Dale, A.M., 2013. Probing tissue microstructure with restriction spectrum imaging: Histological and theoretical validation. 
Hum. Brain Mapp. 34, 327-346.

Widjaja, E., Blaser, S., Miller, E., Kassner, A., Shannon, P., Chuang, S.H., Snead, O.C., Raybaud, C.R., 2007. Evaluation of subcortical white matter and deep white matter tracts in malformations of cortical development. Epilepsia 48, 1460-1469.

Widjaja, E., Kis, A., Go, C., Raybaud, C., Snead, O.C., Smith, M.L., 2013. Abnormal white matter on diffusion tensor imaging in children with new-onset seizures. Epilepsy Res. 104, 105-111.

Widjaja, E., Zamyadi, M., Raybaud, C., Snead, O.C., Doesburg, S.M., Smith, M.L., 2015. Disrupted global and regional structural networks and subnetworks in children with localization-related epilepsy. Am. J. Neuroradiol. 36, 1362-1368.

Widjaja, E., Zarei Mahmoodabadi, S., Otsubo, H., Snead, O.C., Holowka, S., Bells, S., Raybaud, C., 2009. Subcortical alterations in tissue microstructure adjacent to focal cortical dysplasia: detection at diffusion-tensor MR imaging by using magnetoencephalographic dipole cluster localization. Radiology 251, 206-215.

Winston, G.P., Micallef, C., Symms, M.R., Alexander, D.C., Duncan, J.S., Zhang, H., 2014. Advanced diffusion imaging sequences could aid assessing patients with focal cortical dysplasia and epilepsy. Epilepsy Res. 108, 336-339.

Winston, G.P., Stretton, J., Sidhu, M.K., Symms, M.R., Thompson, P.J., Duncan, J.S., 2013. Structural correlates of impaired working memory in hippocampal sclerosis. Epilepsia 54, 1143-1153.

Wu, E.X., Cheung, M.M., 2010. MR diffusion kurtosis imaging for neural tissue characterization. NMR Biomed. 23, 836-848.

Yogarajah, M., Powell, H.W.R., Parker, G.J.M., Alexander, D.C., Thompson, P.J., Symms, M.R., Boulby, P., Wheeler-Kingshott, C.A., Barker, G.J., Koepp, M.J., Duncan, J.S., 2008. Tractography of the parahippocampal gyrus and material specific memory impairment in unilateral temporal lobe epilepsy. Neuroimage 40, 1755-1764.

Zhang, H., Schneider, T., Wheeler-Kingshott, C.A., Alexander, D.C., 2012. NODDI: Practical in vivo neurite orientation dispersion and density imaging of the human brain. Neuroimage 61, $1000-1016$.

Zucca, I., Milesi, G., Medici, V., Tassi, L., Cardinale, F., Tringali, G., Colombo, N., Incerti, L.D., Freri, E., Morbin, M., Figini, M., Spreafico, R., Garbelli, R., Garbelli, R., 2016. Type II FCD : ex vivo 7 Tesla MRI abnormalities and histopathological comparisons. Ann. Neurol. 79, 4258. 
Table. Neuropathology studies and markers used for the investigation of white matter pathology in epilepsy.

\begin{tabular}{|c|c|c|c|c|}
\hline $\begin{array}{l}\text { Structure/ } \\
\text { cell types }\end{array}$ & Components & Stains/ Markers & $\begin{array}{l}\text { Techniques of } \\
\text { quantification }\end{array}$ & Examples of studies \\
\hline Axons & $\begin{array}{l}\text { Size } \\
\text { Fibre density }\end{array}$ & $\begin{array}{l}\text { Neurofilament (Light, medium } \\
\text { and heavy chain) } \\
\text { (e.g. SMI31) }\end{array}$ & $\begin{array}{l}\text { Quantitative } \\
\text { Immunohistochemistry } \\
\text { Electron microscopy }\end{array}$ & $\begin{array}{l}\text { (Shepherd et al., 2013) } \\
\text { (Garbelli et al., 2012) }\end{array}$ \\
\hline \multirow[t]{4}{*}{$\begin{array}{l}\text { Myelin and } \\
\text { oligodendroglial } \\
\text { lineage }\end{array}$} & Myelin sheath & $\begin{array}{l}\text { Luxol fast Blue stain } \\
\text { Myelin Basic protein } \\
\text { CNPase }\end{array}$ & $\begin{array}{l}\text { Quantitative } \\
\text { Immunohistochemistry } \\
\text { e.g. labelling index } \\
\text { Quantitative MRI } \\
\text { correlation (in-vivo and } \\
\text { ex-vivo) }\end{array}$ & $\begin{array}{l}\text { (Lockwood-Estrin et al., 2012; } \\
\text { Mühlebner et al., 2012; Shepherd } \\
\text { et al., 2013; Thom et al., 2012) } \\
\text { (Lockwood-Estrin et al., 2012; } \\
\text { Reeves et al., 2016; Thom et al., } \\
\text { 2012) }\end{array}$ \\
\hline & $\begin{array}{l}\text { Oligodendrocytes } \\
\text { (mature/precursor } \\
\text { cells) }\end{array}$ & $\begin{array}{l}\text { Olig1, Olig2, } \\
\text { Myelin basic protein } \\
\text { CNPase } \\
\text { NogoA }\end{array}$ & $\begin{array}{l}\text { Quantitative / qualitative } \\
\text { immunohistochemistry }\end{array}$ & $\begin{array}{l}\text { (Lockwood-Estrin et al., 2012; } \\
\text { Mühlebner et al., 2012; Scholl et } \\
\text { al., 2017; Shepherd et al., 2013; } \\
\text { Thom et al., 2012; Zucca et al., } \\
\text { 2016) }\end{array}$ \\
\hline & & Tppp7/p25 & $\begin{array}{l}\text { Stereology } \\
2-d \text { cell counting }\end{array}$ & (Scholl et al., 2017) \\
\hline & $\begin{array}{l}\text { Oligodendroglial } \\
\text { progenitor cells }\end{array}$ & $\begin{array}{l}\text { NG-2, PDGFR } \alpha \text {, PDGFR } \beta \text {. } \\
\text { Ki67 }\end{array}$ & $\begin{array}{l}\text { Immunohistochemistry/ } \\
\text { double labelling to } \\
\text { quantify proliferative } \\
\text { cell fractions }\end{array}$ & $\begin{array}{l}\text { (Scholl et al., 2017; Shepherd et } \\
\text { al., 2013) }\end{array}$ \\
\hline \multirow[t]{2}{*}{ Astroglia } & Mature & GFAP & $\begin{array}{l}\text { 2-d cell counting } \\
\text { Quantitative } \\
\text { Immunohistochemistry } \\
\text { e.g. labelling index }\end{array}$ & $\begin{array}{l}\text { (Lockwood-Estrin et al., 2012; } \\
\text { Reeves et al., 2016; Thom et al., } \\
\text { 2012) }\end{array}$ \\
\hline & $\begin{array}{l}\text { Immature, reactive } \\
\text { glia }\end{array}$ & Nestin, & $\begin{array}{l}\text { Quantitative } \\
\text { Immunohistochemistry }\end{array}$ & (Reeves et al., 2016) \\
\hline \multirow[t]{3}{*}{$\begin{array}{l}\text { White matter } \\
\text { neurones }\end{array}$} & All neuronal types & $\begin{array}{l}\text { Cresyl Violet (Nissl) } \\
\text { NeuN } \\
\text { Map2 }\end{array}$ & $\begin{array}{l}\text { Stereology } / 3 \mathrm{~d} \text { cell } \\
\text { counting } \\
\text { 2-d cell counting } \\
\text { WSS image analysis }\end{array}$ & $\begin{array}{l}\text { (Eriksson et al., 2006; Hardiman } \\
\text { et al., 1988; J. Y. Liu et al., } \\
\text { 2014) }\end{array}$ \\
\hline & $\begin{array}{l}\text { Inhibitory } \\
\text { interneurons subsets }\end{array}$ & $\begin{array}{l}\text { Calbindin, Parvalbumin, } \\
\text { calretinin, NPY, Somatostatin, }\end{array}$ & 2-d cell counting & $\begin{array}{l}\text { (Richter et al., 2016; Suárez-Solá } \\
\text { et al., 2009) }\end{array}$ \\
\hline & Immature, subplate & Tbr1 & 2-d cell counting & (Richter et al., 2016) \\
\hline
\end{tabular}

These markers have been used in comparative investigation with normal control white matter, mainly using light microscopy on fixed tissue specimens. Cited studies exclude those on vascular structures and inflammatory microglial cells. The main methods employed include quantitative immunohistochemistry to evaluate the 'labelling index' of a structure, stereology (3D cell counting) to quantify cell density and whole slides scanning analysis (WSS) to study wide regions of brain rapidly and automatically. 


\section{Legend for figures.}

Figure 1. Neuropathology and ultra-high field MRI study of the white matter. (A) Subcortical myelin pallor is identified in a luxol fast blue (LFB) stain for the white matter in the depth of a sulcus in the region of the cortical U fibers in a case of MRI-occult FCD IIB (arrow head). (B) Increased and abnormal horizontal neurons highlighted by MAP2 in the subcortical white matter in FCD IIB. (C). NeuN labelling of grey matter and white matter neurons. (D-F). Whole slide scanning analysis (adapted from (J. Y. Liu et al., 2014) is a powerful tool to quantify interstitial neuronal number in extensive areas of white matter (Definiens Tissue Studio, Munich, Germany): NeuN stained section is first scanned (D) and then tessellated maps are built up segregating compartments of white matter from cortex according to the neuronal density (E); With this method the system can be taught to define areas with intermediate neuronal density (F). In this example cortical layer I and the subplate zone (shown in green) are distinct from regions with high neuronal density (the cortex in orange) and low neuronal density (the deep white matter in yellow). The total number in each compartment can be automatically measured and this algorithm can be applied to many cases with the same immunostaining. G) 9.4 T T2-weighted MRI of fixed resected tissue can be used to co-register and quantify MRI values with pathology measurements, to detect and correlate subtle variations in white matter axonal density with neurofilament stain $(\mathrm{H})$ and myelin (I).

Figure 2. Histological correlates of reduced white matter fractional anisotropy (FA) in TLE patients. (A) The fornix approximated by probabilistic tractography of an unbiased template; this particular tract has shown reduced FA bilaterally, and analysis of resected specimens has shown that such changes correspond to reduced axonal density, which is most apparent in patients with marked hippocampal sclerosis (B) than in those with minimal pathology (C). Adapted from (Concha et al., 2010)

Figure 3. Connectome analysis. Top: Whole-brain diffusion MRI tractographic assessments provide a non-invasive means to approximate white fiber tracts connecting different parts of the brain. Middle: The generation of connectomes, i.e., descriptions of connectivity between all brain regions, often requires to first subdivide the brain into different areas using parcellation techniques. The systematic assessment of connectivity strength between all pairs of parcels can then be used to build a connectivity matrix, which is mathematically equivalent to a graph (where nodes represent the regions, and edges the connections between them). Bottom: Connectomes can be analyzed using graph theory, a mathematical framework to formalize network topology. Network clustering and path length are fundamental and complementary topological parameters. Clustering relates to the local efficiency of the network. Conversely, the inverse of path length relates to global efficiency. 

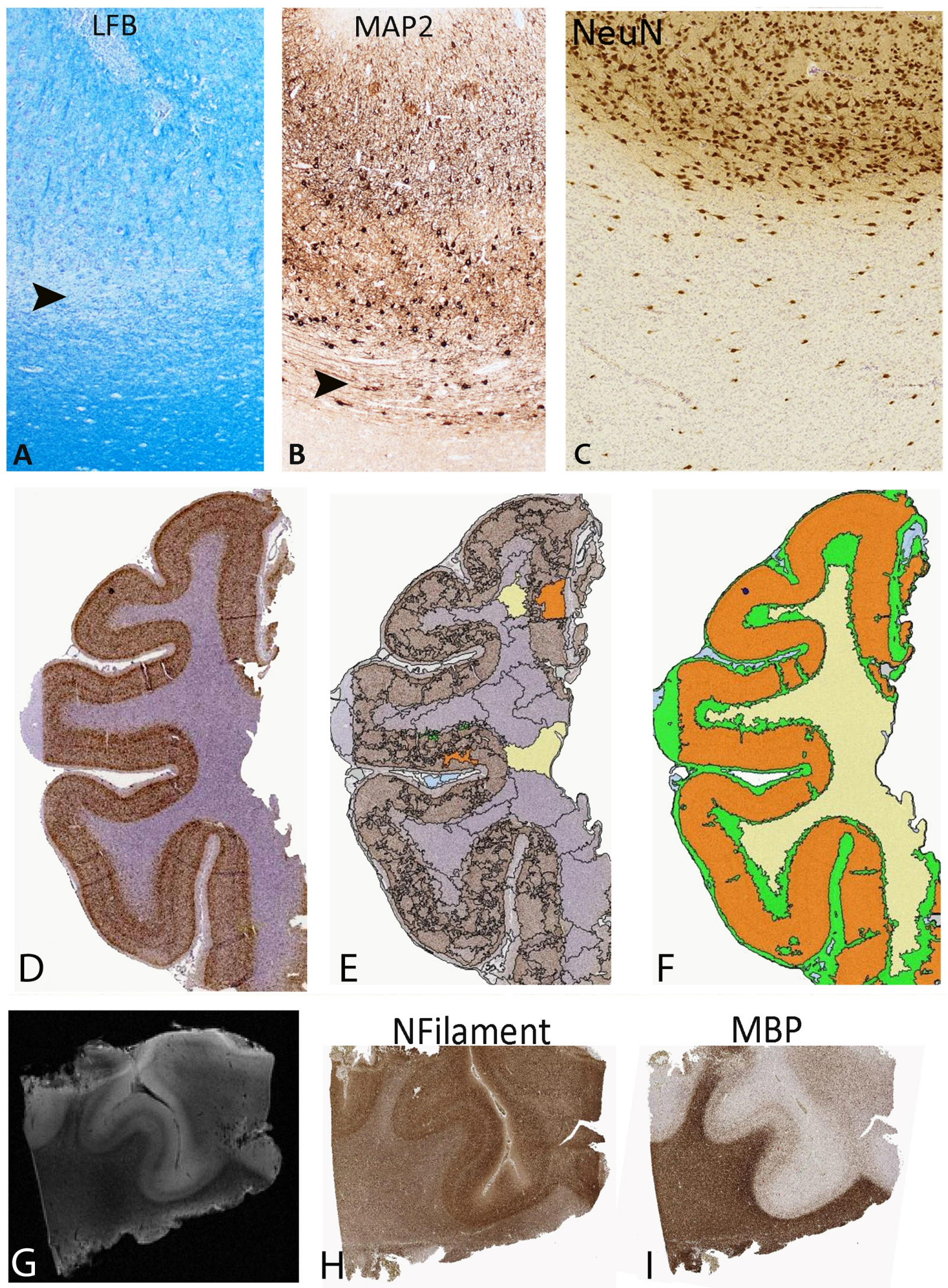


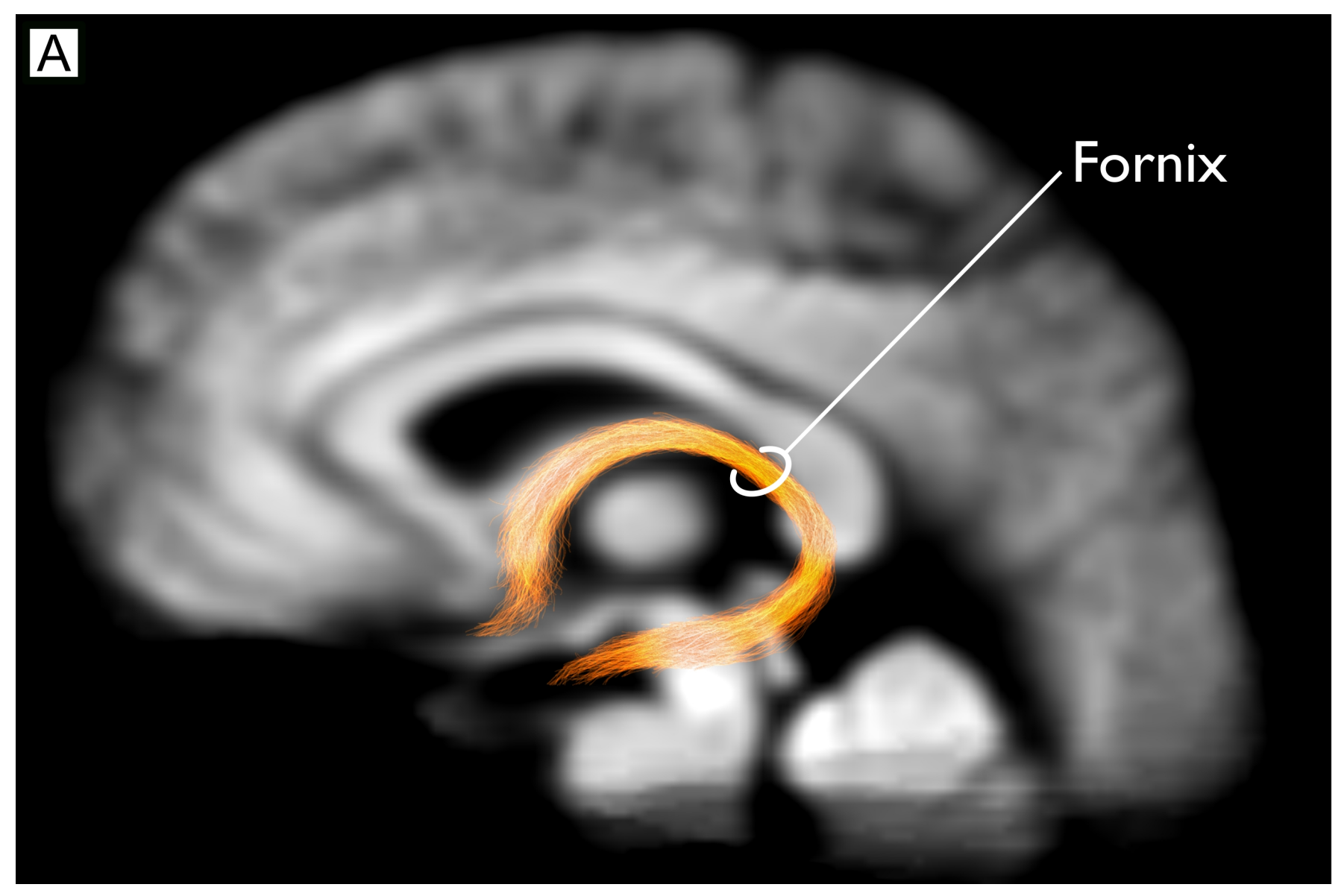
B is cos os - ocis o duo - Oo jona 50.05

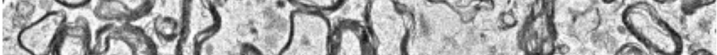

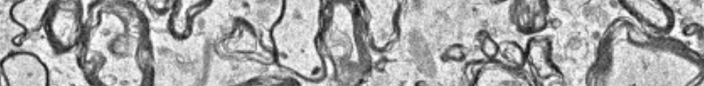

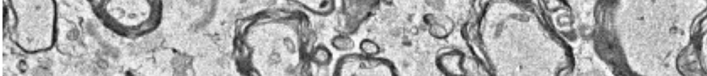
10020 s.t.

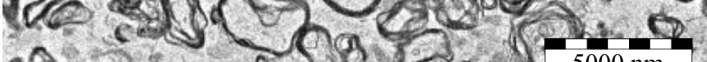

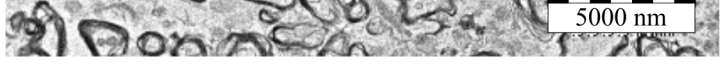
c] 1 ons orrous

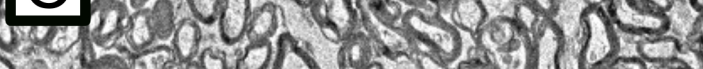
- 0000 s 0 .

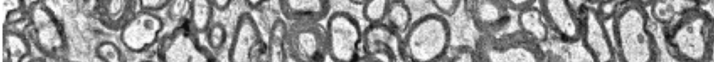

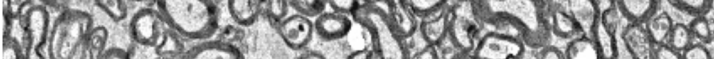

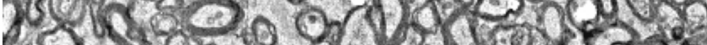
co vo 20 a 5 .

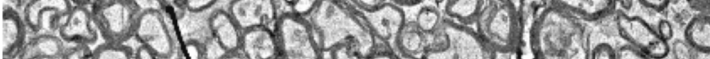
- 2048 un 1700

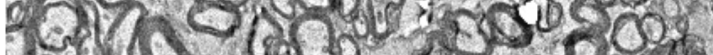
noviso en os.

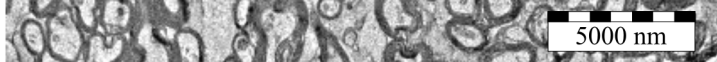



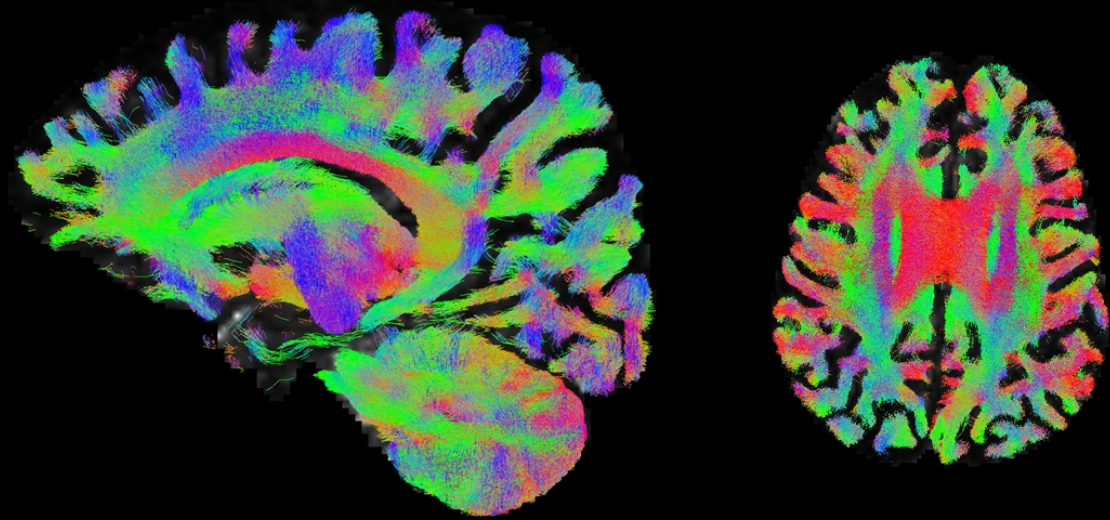

WHOLE-BRAIN DIFFUSION TRACTOGRAPHY

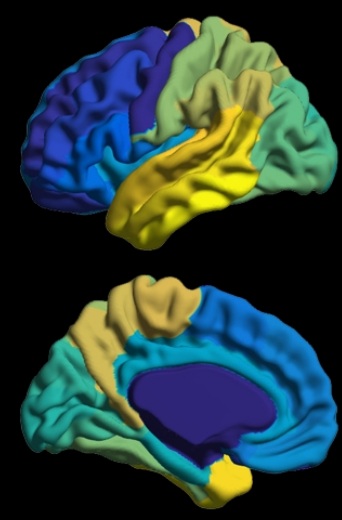

PARCELLATION

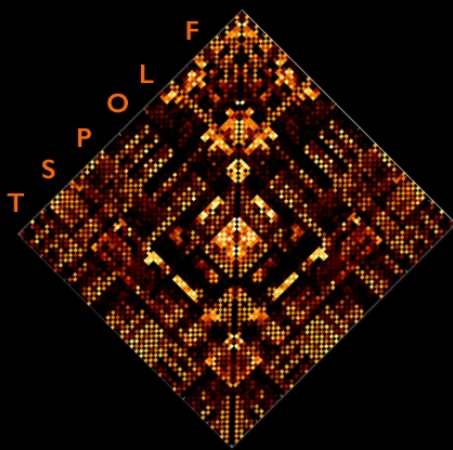

PARCEL-TO-PARCEL CONNECTIVITY

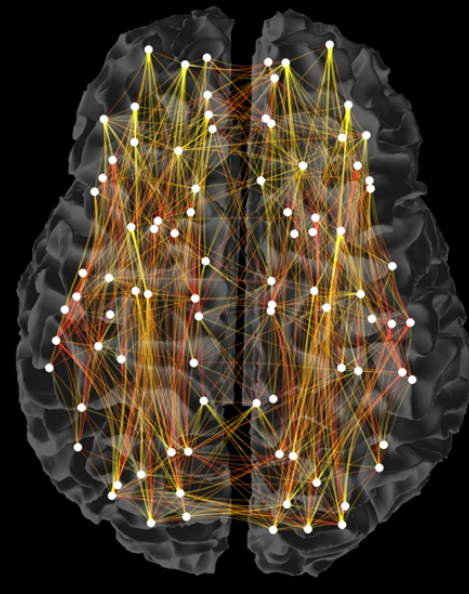

GRAPH

CONNECTOME GENERATION<smiles>[2H]C([2H])([2H])O</smiles>

LOW

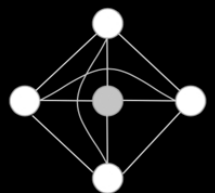

HIGH

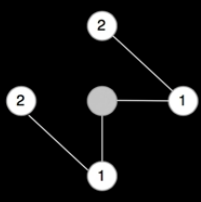

LOW

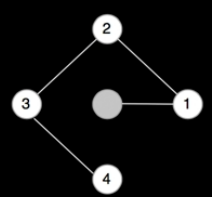

HIGH

CLUSTERING

PATH LENGTH

GRAPH-THEORETICAL PARAMETERIZATION 